Мазняк М. М., Тихонова О. В.

Аннотация. Цель исследования - дать систематическое описание лингвистического феномена, называемого «португальское алхамиадо» или «португальская алжамиа». Научная новизна исследования состоит в том, что впервые в отечественной португалистике рассматривается данное явление с точки зрения исторической фонетики португальского языка, в частности особенности транслитерации арабской буквы шйн [š]. В результате показано, что буква шйн [̌̌s] не всегда используется для обозначения звуков, передаваемых латинской s (и х), как это указал Д. Лопеш в таблицах норм транслитерации арабо-португальских текстов. Часто для указания на звуки, передаваемые буквой $\mathrm{s}$ в интервокальной позиции, используется арабская буква джйм [ั̆], которую Д. Лопеш предлагал транслитерировать как ј.

\title{
Alternative Transliterations of a Portuguese Sound [s] in Portuguese Aljamia Texts of the XVI Century
}

\author{
Mazniak M. M., Tikhonova O. V.
}

Abstract. The paper provides a systemic description of a linguistic phenomenon called "Portuguese Aljamia". Scientific originality of the research lies in the fact that for the first time in domestic Portuguese studies this phenomenon is examined from the viewpoint of historical phonetics, in particular, the authors analyse alternative transliterations of a Portuguese sound [s]. The findings indicate that the letter šin [š] is not always used to transliterate Portuguese sound [s], as it was proposed by D. Lopes in his Arabic Transliteration Rules. Intervocalic [s] is often transliterated as [ğ]. According to D. Lopes, this Arabic letter should be transliterated as [j].

\section{Введение}

Актуальность темы исследования заключается в том, что в условиях возросшего интереса к межкультурной коммуникации в различных научных дисциплинах впервые в отечественной традиции проводится систематический анализ лингвокультурологического явления, известного как португальское алхамиадо (или португальские тексты в арабской графике). В этих документах средствами арабского алфавита передаются звуки португальского языка в письмах арабских подданных португальской короны в Марокко к суверену. Эти рукописи из королевской канцелярии датируются началом XVI в. и представляют собой ценнейший материал по португальской фонетике этого исторического периода.

Для достижения цели исследования следует решить следующие задачи: 1) проанализировать особенности употребления арабской буквы шйн [š] в арабо-португальских документах; 2) проанализировать особенности

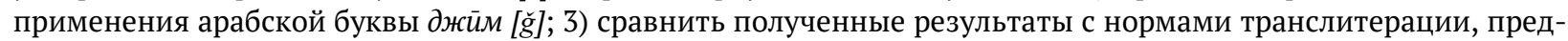
ложенными португальским арабистом Д. Лопешом; 4) установить причину отклонения указанных букв от правил, предложенных Д. Лопешом.

Наряду с разрабатываемыми сравнительным (по преимуществу историко-фонетическим) и палеографическим (и текстологическим) методами анализа памятников на алхамиадо в исследовании использовались методы филологического и сравнительно-исторического анализа текстов.

Теоретическая база исследования - труды зарубежных авторов (преимущественно на португальском языке) по историко-культурным и филологическим аспектам явления, называемого португальское алхамиадо или португальская алжамия (Lopes, 1897; Harvey, 1986; Giese, 1931; Drumond Braga, 2008; Teyssier, 1974; Teixeira, 2006).

Практическая значимость работы состоит в возможности использовать полученные данные в научных исследованиях, а также в учебной деятельности. Материалы работы могут применяться на практических 
занятиях по португальскому языку, на семинарах и в лекционных курсах по истории португальского языка (в частности, в вопросах исторической фонетики) и истории Португалии.

История вопроса. Феномен португальского алхамиадо не столь распространен и детально изучен как испанское алхамиадо. На сегодня вопросам португальского алхамиадо или португальской алжамии посвящены единичные работы за рубежом, а в отечественной традиции они вовсе не освещались. Среди наиболее значимых работ можно выделить труды ряда ученых (Harvey, 1986; Giese, 1931; Drumond Braga, 2008, с. 113; Teyssier, 1974; Teixeira, 2006).

\section{Основная часть}

Алхамиа (порт. aljaтia) или португальское алхамиадо - это средневековые тексты на португальском языке в арабской графике (Harvey, 1986, с. 1) или текст, в котором звуки неарабского языка воспроизводятся арабскими буквами (DLP, 2001, с. 177). Арабо-португальские тексты на алхамиадо не получили такого распространения, как арабо-испанские, в силу исторических особенностей развития этого феномена в португальских колониях. Эта проблема не сводима к трудностям при передаче носовых португальских гласных, как это полагал Д. Лопеш (Lopes, 1897, c. xviii-xxx; Harvey, 1986, с. 8-11). Хотя ко времени написания рассматриваемых документов в португальском языке наблюдались некоторые заметные изменения: в частности, в фонетике активно шел процесс назализации гласных (Мазняк, Тихонова, 2020а).

Д. Лопеш при публикации арабо-португальских документов разработал правила транслитерации этих текстов, опираясь на нормы транслитерации текстов на испанском алхамиадо (Мазняк, Тихонова, 2020b). В таблице соответствия португальского и арабского алфавитов Д. Лопеш указал, что буква шӣн [̌̌s] должна

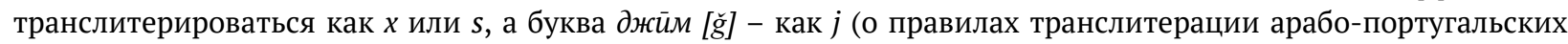
текстов см.: Мазняк, Тихонова, 2021; Lopes, 1897, с. хviii-xxх; Мазняк, Тихонова, 2020b; о фонетических характеристиках арабских фонем см.: Юшманов, 1985).

Действительно, в португальских документах чаще всего шйн [š] встречается для обозначения звуков, передаваемых латинской $s$ (891 пример). Однако на втором месте по частотности шйн [š] транслитерируется не как $x$ (46 примеров), а как ss (178 примеров). Кроме того, шйн [̌̌ чаемых латинскими $c h$ (20 примеров), с̧ и c(i/e) (15 примеров), а также $z$ (11 примеров) и $j$ (1 пример). Во всех этих функциях шйн [š] чередуется с другими арабскими буквами. Хотя Д. Лопеш не отмечает это особо, но чаще всего шйн $[\check{s}]$ чередуется с функции шйн [̌̌s] также чередуется с сйн [s] (40 примеров). Встречаются и другие чередования (см. Таблицу 1).

Таблица 1. Транслитерация шӣн [šs] и джӣм [ร̆] в португальском алхамиадо

\begin{tabular}{|c|c|c|c|c|c|c|c|c|c|c|c|}
\hline & $S$ & sS & $x$ & ch & $c ̧, c(i / e)$ & $z$ & $j$ & $g(i / e)$ & $h$ & $t$ & Всего \\
\hline uийн [š] & 891 & 178 & 46 & 20 & 15 & 11 & 1 & - & - & - & 1163 \\
\hline 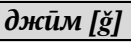 & 110 & - & - & 3 & 1 & 1 & 27 & 17 & 1 & - & 160 \\
\hline$c \bar{u} \boldsymbol{H}[s]$ & 40 & 4 & 3 & 1 & 153 & 20 & - & - & - & 1 & 222 \\
\hline cad [ș] & 3 & - & - & - & 11 & - & - & - & - & 1 & 15 \\
\hline 3ай $[z]$ & 1 & - & - & - & - & 166 & - & - & - & - & 167 \\
\hline
\end{tabular}

Как отмечалось, буква шӣн [š] в основном используется для передачи звуков, обозначаемых латинской $s$ (891 пример) (см. Таблицу 2).

Таблица 2. Буква шйн [š] в транслитерации s

\begin{tabular}{|c|c|c|}
\hline Алхамиадо & DIN (2021) & Португальский \\
\hline شَنْنُزْ & [šinuwr'] & senhor $(1: 1)$ \\
\hline 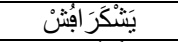 & [yiš̌k'kāāfuš́n & escravos $(2: 6)$ \\
\hline 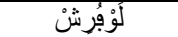 & [luw'furiš'] & lavoures $(1: 2)$ \\
\hline
\end{tabular}

В данном исследовании после примера в скобках первая цифра указывает номер документа в издании Д. Лопеша 1897 г., вторая - строку.

Как видно из Таблицы 3, буква шӣн [š] не используется для передачи звуков, обозначаемых латинской $s$ в интервокальной позиции. В этой функции всегда используется джйм [ğ]: quiser (7:7) [12], casa (1:5) [10], cousa (3:30) [10], deshonra (6:46) [7], causa (4:5) [4], deseja (8:44) [3], presente (7:53) [3], misericordioso (2:3) [2] и др.

Таблица 3. Буква джӣм [ั̆] в транслитерации s в интервокальной позиции

\begin{tabular}{|c|c|c|}
\hline Алхамиадо & DIN (2021) & Португальский \\
\hline كجَازْ & [kğār'] & quiser (7:7) [12] \\
\hline كُاجَ & [kāğa] & casa $(1: 5)[10]$ \\
\hline كُوُْجَ & [kuw'ğa] & cousa $(3: 30)[10]$ \\
\hline
\end{tabular}


Буква джйм [ğ] встречается в двух словах в стечении с согласными (4 примера) (см. Таблицу 4).

Таблица 4. Буква джйм [ั̆] в транслитерации з в стечении с согласными

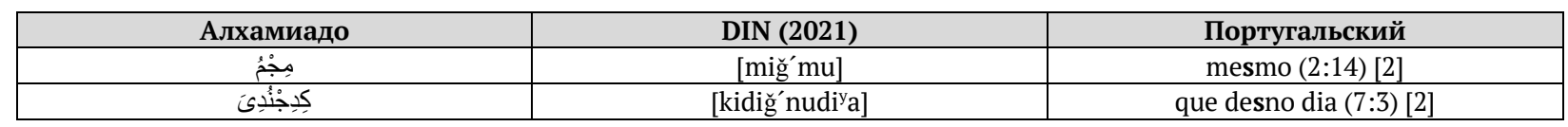

В этих примерах джӣм [̌̆] используется для обозначения звуков, обозначаемых $s$ перед звонким согласным (m, n).

Буква джйм [ğ] встречается и в конце слова, однако в этом случае она находится в интервокальной пози-

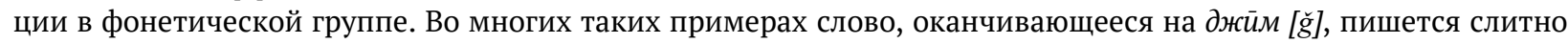
с последующим словом (см. Таблицу 5).

Таблица 5. Буква джӣм [ั̆] в транслитерации s в фонетической группе

\begin{tabular}{|c|c|c|}
\hline Алхамиадо & DIN (2021) & Португальский \\
\hline لـُجَلَرِْْشْن & [duğalar'fišs'] & dos alarves (3:4) \\
\hline 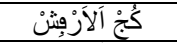 & [kuğg' alār'fišs'] & com os alarves $(6: 97)$ \\
\hline نُجَلَرِْْشْنَ & [nuğalar'fiš̌́] & nos alarves $(3: 25)$ \\
\hline ظُرْبْجِجمُشْن & [zar'fuğimuš́] & dar vos-hemos (8:38) \\
\hline بُوجُتْزُشُشْ & [fuwğut'ruš'] & vós outros (8:39) \\
\hline
\end{tabular}

Первое слово в такой фонетической группе - обычно артикль или местоимение.

Также со звонкой гласной (см. Таблицу 6).

Таблица 6. Буква джӣм [ğ] в транслитерации s в фонетической группе

\begin{tabular}{|c|c|c|}
\hline Алхамиадо & DIN (2021) & Португальский \\
\hline كِيَجْمِنَشْن كَرْطُشْ & 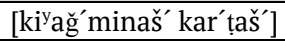 & que as minhas cartas (1:4) \\
\hline تِرِجْ دِيَشْن & {$\left[\mathrm{t}^{\mathrm{i}} \mathrm{riğg}^{\prime} \mathrm{di}^{\mathrm{y}} \mathrm{y}^{\circ} \mathrm{s}^{\prime}\right]$} & três dias $(1: 8)$ \\
\hline 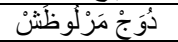 & 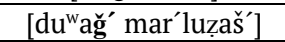 & duas marlotas (4:9) \\
\hline 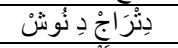 & [dit'rāḡǵ di nuwš'] & detrás de nós (6:32) \\
\hline دَجْ لَنْسصَشْ & [daǧ́lan'sșaš'] & das lanças $(7: 74)$ \\
\hline لدُجْ مَعَوُشُشْ دِيَاشُْ & 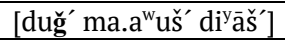 & dos meus dias (7:92) \\
\hline
\end{tabular}

Только в двух словах джӣм [ğ] используется для передачи звуков, обозначаемых латинской $s$ в конце слова перед словом, начинающимся с глухого согласного в составе фонетической группы (1 пример); либо в конце слова, замыкающего фонетическую группу (4 примера) (см. Таблицу 7).

Таблица 7. Буква джӣм [ğ] в транслитерации s в фонетической группе

\begin{tabular}{|c|c|c|}
\hline Алхамиадо & DIN (2021) & Португальский \\
\hline 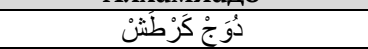 & 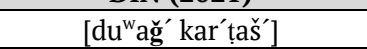 & duas cartas $(3: 2)$ \\
\hline 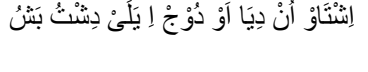 & 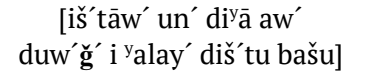 & $\begin{array}{l}\text { estou um dia ou dous, } \\
\text { e além disto passo ( } 7: 31)\end{array}$ \\
\hline أَبِرِمَيَرْرُ دِيَ دُ مِبْ & [u bir' may'ru diª du miğ'] & o primeiro dia do mês (3:39) \\
\hline كُوْجَجْ كِبَشَقَوْ & {$\left[\right.$ kuw' ğăg $^{\prime}$ ki bašafaw'] } & cousas que passavam $(6: 3)$ \\
\hline مَنْدَرْ مَجَ بُرْ بُسُبَجْ & [man'dar' mağa bur' yusuf'] & mandarmos por Iuçafe (4:10-11) \\
\hline
\end{tabular}

Единственный пример, в котором буква джйм [ğ] используется для передачи звука, обозначаемого буквой $s$ в фонетической группе перед словом, начинающимся с глухого согласного: duas cartas [duw $a \check{\boldsymbol{g}}^{\prime}$ kar'taš'] (3:2). В другом примере слово dous находится в конце фонетической группы; тем не менее оно также записано с буквой джйм [̌̆]. Таким образом, во всех формах слова dous для передачи звука, обозначаемого буквой $s$, используется буква джйм [ั̆].

В примере cousas que passavam (6:3), возможно, конечное $s$ транслитерировано как джйм [ğ] по аналогии с $s$ в начале того же слога.

В примере mas por Iuçafe (4:11) слово, транслитерированное Д. Лопешом как таs, написано с огласовкой

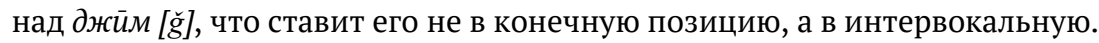

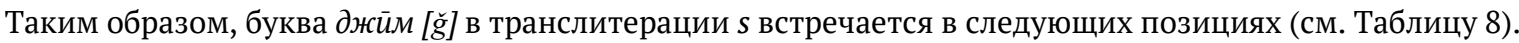

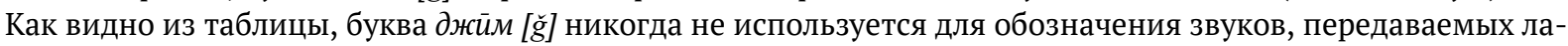
тинской $s$ в начальной позиции; и редко используется с этой целью в конечной позиции (4 примера) или в стечении с глухим согласным в постпозиции (1 пример). Чаще всего в этой функции джйм [ğ] используется в интервокальной позиции (93 примера) или в стечении со звонким согласным в постпозиции (22 примера). 
Таблица 8. Буква джйм [ร̆] в транслитерации s: позиция в слове и в фонетической группе

\begin{tabular}{|l|c|c|c|}
\hline & В отд. слове & $\begin{array}{c}\text { В составе фонет. гр. } \\
\text { (в кон. поз. в слове) }\end{array}$ & Всего \\
\hline В нач. поз. & - & - & - \\
\hline В интервок. поз. & 73 & 10 & $\mathbf{9 3}$ \\
\hline В стеч. с согл. (перед зв. согл.) & 4 & 18 & $\mathbf{2 2}$ \\
\hline В стеч. с согл. (перед глух. согл.) & - & 1 & $\mathbf{1}$ \\
\hline В кон. поз. & - & 4 & $\mathbf{1 1 0}$ \\
\hline Всего & $\mathbf{7 7}$ & 33 & \\
\hline
\end{tabular}

В некоторых словах встречается чередование джӣм [ร̌] и шӣн [š] при транслитерации $s$ (см. Таблицу 9).

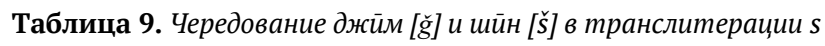

\begin{tabular}{|c|c|c|c|}
\hline Араб. буква & Алхамиадо & DIN (2021) & Португальский \\
\hline \multicolumn{4}{|c|}{ В интервокальной позиции в отдельном слове } \\
\hline$\partial \% \bar{u} M[\check{g}]$ & دِجُنْرَ| & [diğun'rā] & deshonra (6:46) [7] \\
\hline ий̈н [š] & 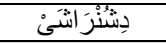 & [dišun'rāšay'] & deshonrassem $(6: 6)$ \\
\hline \multicolumn{4}{|c|}{ В интервокальной позиции в фонет. группе } \\
\hline 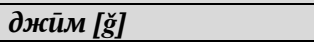 & 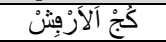 & [kuğ' alār'fišs'] & com os alarves $(6: 97)[3]$ \\
\hline 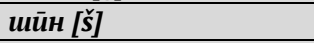 & 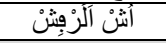 & [uš' alār'fišs] & os alarves $(6: 15)$ \\
\hline \multicolumn{4}{|c|}{ В стечении с согласными } \\
\hline джӣм [气̆] & اَججمتَدَابَ & [ağ'man'dāfa] & as-mandava $(7: 51)[8]$ \\
\hline ийн [š] & أَثْبْغَغَاشْن & [aš'bagaš'] & as pagas $(6: 13)$ \\
\hline
\end{tabular}

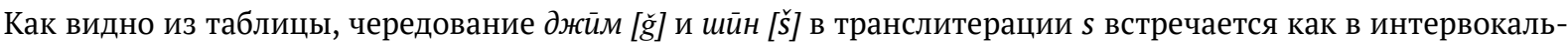
ной позиции в отдельном слове, так и в фонетической группе. В стечении с согласным это чередование также встречается, однако шӣн [̌̌s] используется в позиции перед глухим, а не звонким согласным.

\section{Заключение}

Таким образом, мы приходим к следующим выводам. В отличие от испанского алхамиадо, на которое опирался Д. Лопеш и в котором нормы транслитерации арабографических текстов более стабильны, в португальском алхамиадо буква шйн [š] используется не только для передачи звуков, обозначаемых латинскими $x$ или $s$, но и некоторыми другими латинскими буквами: $s s, x, c h, c ̧, c(i / e), z, j$. Однако употребление буквы шйн [š] с целью передачи звуков португальского языка, обозначаемых латинской $s$, ограничено позицией последней. Буква $ш \bar{u} н[\check{s}]$ может передавать только те звуки португальского языка, которые обозначаются $s$ в начале, конце слова или в стечении с согласными, но только в позиции перед глухим согласным. В позиции перед звонким согласным или в интервокальной позиции в слове или в фонетической группе с этой целью используется буква

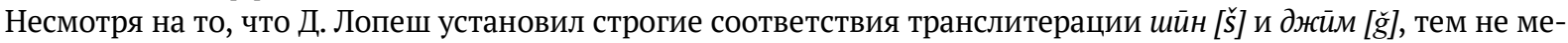
нее в текстах он сам отклоняется от этих правил и транслитерирует указанные буквы вопреки рекомендованным им же правилам. Очевидно, что транслитерация этих букв не сводится к принятым в испанским алхамиадо $x / s$ и $j$. Связано это с тем, что в отличие от испанского португальское алхамиадо имеет не строго конвенциональный характер, а потому более непосредственно и точно передает звуки другого языка (португальского). Таким образом, во избежание неверной транслитерации следует либо расширить таблицу соответствий, либо уточнить это положение в примечании к таблице.

Перспективы дальнейшего исследования мы видим в изучении других орфографических функций как вышеназванных арабских букв, так и других, используемых в португальских текстах на алхамиадо.

\section{Источники | References}

1. Мазняк М. М., Тихонова О. В. Особенности орфографии португальских текстов в арабской графике XVI в. // Филологические науки. Вопросы теории и практики. 2021. Т. 14. Вып. 12.

2. Мазняк М. М., Тихонова О. В. Особенности применения арабских букв та $\overrightarrow{\mathrm{t}}]$ и $3 \overrightarrow{\mathrm{a}}[\mathrm{z}]$ для передачи звуков, обозначаемых латинской буквой t в португальских рукописях на алжамии XVI в. // Stephanos. 2020a. № 6 (44).

3. Мазняк М. М., Тихонова О. В. Португальская алжамиа: португальские тексты в арабской графике XVI в. // Вестник Московского университета. Серия 9 «Филология». 2020b. № 2.

4. Юшманов Н. В. Грамматика литературного арабского языка. Изд-е 3-е. М.: Наука, 1985.

5. DIN. Deutsches Institut für Normung. 2021. URL: https://www.din.de/de

6. DLP. Dicionário da Língua Portuguesa Contemporânea da Academia das Ciências de Lisboa. Lisboa: Editorial Verbo, 2001. 
7. Drumond Braga I. Do árabe e do aljamiado em Portugal // Anaquel de estudios árabes. Anejo I. Serie de monografías. Madrid: Universidad Complutense de Madrid, 2008.

8. Giese W.Como os mouros de Asfi grafavam o português // Biblos. 1931. № 7.

9. Harvey L. P. Aljamia Portuguesa Revisited // Portuguese Studies Review. 1986. № 2.

10. Lopes D. Textos em aljamia portuguesa: documentos para a história do domínio português em Safim. Lisboa: Imprensa Nacional, 1897.

11. Teixeira S. F. L. Apontamentos para uma edição semidiplomática em aljamia portuguesa. Rio de Janeiro: UFRJ; Faculdad de de Letras, 2006.

12. Teyssier P. Les textes en "Aljamia” portugaise: ce qurils nous, apprennent sur la prononciation du portugais au début du XVIe siècle. Separata de Actas do XIV Congresso Internacional de Lingüística e Filologia Românicas. Napoli: Macchiaroli, 1974.

\section{Информация об авторах | Author information}

RU Мазняк Мария Михайловна ${ }^{1}$, к. филол. н.

Тихонова Оксана Викторовна ${ }^{2}$, к. филол. н.

1,2 Санкт-Петербургский государственный университет

EN Mazniak Maria Mikhailovna ${ }^{1}, \mathrm{PhD}$

Tikhonova Oxana Viktorovna ${ }^{2}, \mathrm{PhD}$

${ }^{1,2}$ Saint Petersburg University

11mmmazniak@mail.ru,2pajaro@mail.ru

\section{Информация о статье | About this article}

Дата поступления рукописи (received): 24.11.2021; опубликовано (published): 28.02.2022.

Ключевые слова (keywords): португальское алхамиадо; алжамиа; арабографические тексты; арабо-португальские рукописи; чередование шйн [š] и джйм [气̆]; Portuguese Aljamia; Aljamia; Arabic script texts; Aljamiado manuscripts; alternation of $[\check{s}]$ and $[\check{g}]$. 